ArDIn. Arte, Diseño e Ingeniería

e-ISSN: 2254-8319

DOI: $10.20868 /$ ardin.2020.9.4125

\title{
Estrategias de dinamización \\ de la enseñanza online del diseño \\ Dynamization Strategies for Online Teaching of Design
}

\author{
Ma BegoñaYáñez Martínez \\ DiSEA (Diseño, Sociedad, Educación y Arte. Universidad Internacional de La \\ Rioja-UNIR, (España) \\ begona.yanez@unir.net \\ Daniel Vega Borrego \\ DiSEA (Diseño, Sociedad, Educación y Arte. Universidad Internacional de La \\ Rioja-UNIR, (España) \\ daniel.vega@unir.net
}

Recibido / Received: 24/07/2019

Aprobado / Approved: 21/10/2019

\section{Resumen}

El presente artículo aborda la necesidad de dinamizar y humanizar la educación online. Para elloaprovechamos las posibilidades que ofrecen las tecnologías al servicio de la educación para ir más allá en la enseñanza del diseño y el arte, incorporando estrategias innovadoras que motiven a los alumnos y contribuyan al desarrollo de su capacidad de trabajo tanto autónomo como 
colaborativo, a distancia. Para ello presentamos dos experiencias que se han puesto en acción por miembros del grupo de investigación DiSEA de UNIR, en las que se aplican las posibilidades de la enseñanza online a distancia, combinadas con facetas más lúdicas y prácticas, ayudando a asimilar los contenidos teóricos mediante la implicación de la experiencia y el protagonismo directo de los alumnos en las acciones educativas. Mostramos resultados que se extraen de estas prácticas como ejemplo de implicación y motivación de los alumnos hacia las tareas propuestas. Las conclusiones de ambas acciones son favorables y aplicables a otras experiencias similares.

Palabras clave: diseño; dinamización; trabajo en equipo; online; videoconferencia; wikis; Adobe Connect

Yáñez Martínez. M.B. y Vega Borrego, D. (2020). Estrategias de dinamización de la enseñanza online del diseño. ArDln. Arte, Diseño $e$ Ingeniería, 9, 77-113.

\section{Abstract}

This article addresses the need to humanize and make dynamic the online education. For that purpose, we will take advantage of the possibilities that education-oriented technologies have to offer. Our research goes beyond the teaching of design and art disciplines and incorporates innovative strategies that encourage students to contribute with their performance capacity in autonomous and collaborative tasks. In this pursuit, we detail two experiences that have been put into action by members of the research group DiSEA from UNIR University. These two approaches apply the possibilities of online distance learning combined with more playful and practical facets. The aim is to help students to assimilate theoretical contents with the involvement of experience and the direct leadership of students in educational actions. We show the results that can be drawn of these practices as examples of implication and motivation of students in relation with the proposed tasks. The conclusions of both actions are positive and can be applied to similar experiences.

Keywords: design; dynamization; teamwork; on-line; videoconference; wikis; Adobe Connect 
Yáñez Martínez. M.B. y Vega Borrego, D. (2020). Dynamization Strategies for Online Teaching of Design. ArDIn. Arte, Diseño e Ingeniería, 9, 77-113.

Sumario / Summary: 1. Introducción. 1.1. Motivación. 2. Objetivos. 2.1. Objetivo general. 2.2. Objetivos específicos. 3.Marco teórico breve. 3.1. Descripción de las aplicaciones utilizadas.4. Método, desarrollo y resultados. 4.1. Brainstorming. 4.1.1. Método. 4.1.2. Desarrollo. 4.1.3. Resultados. 4.2. Wikis. 4.2.1. Método. 4.2.2. Desarrollo. 4.2.3. Resultados. 5. Conclusiones. Referencias.

\section{Introducción}

Los miembros del grupo DiSEA, en el que se enmarca este estudio, tratamos de conjugar en nuestros modos de hacer las premisas que sostienen nuestro grupo de investigación: Diseño, Sociedad, Enseñanza y Arte. Esto nos lleva a la necesidad y al desarrollo natural de unas habilidades que traten de conjugar todos estos aspectos en nuestra práctica docente e investigadora. “Debido a que la Sociedad exige nuevas competencias tanto en el desarrollo profesional como en la práctica educativa, la comunidad educativa no puede quedarse impasible ante este proceso de innovación, eso sí, sin perder su verdadera esencia" (Infante et al., 2007, p. 237).

\subsection{Motivación}

Lo que queremos afrontar con este estudio es una experiencia que marque la diferencia en la forma de impartir la enseñanza online especialmente en los ámbitos del arte y el diseño. Para ello queremos compartir nuestras conclusiones y los resultados aportados por los alumnos, que enriquecen la experiencia, la investigación y nos 
motivan a seguir buscando métodos de innovación, implicación y humanización de la enseñanza online.

A su vez, partimos desde una posición favorable que es el rápido desarrollo de las nuevas tecnologías de la información y la comunicación que permiten implementar estrategias de mejora, motivación y dinamización de las materias. Se trata de un intento de romper las fronteras, en la medida de lo posible, de la distancia. Queremos demostrar que la no presencialidad no debe suponer una reducción de la calidad de la enseñanza de los estudios en los que impartimos, trabajamos, investigamos y experimentamos nuestra propia faceta profesional, creativa y docente.

En nuestra sociedad actual "es preciso [...] que los estudiantes sean capaces de interpretar relaciones complejas y elaborar situaciones creativas; de desarrollar su inteligencia emocional y un aprendizaje autodirigido; que sean comunicadores $y$ productores efectivos; trabajadores colaborativos; consumidores y procesadores de la información diestros; que desarrollen la metacognición; que estén alfabetizados digitalmente y se capaciten para sintetizar ideas diversas". (Tourón y Marín, 2019, p. 18)

\section{Objetivos}

A modo de hipótesis de trabajo partimos de una serie de cuestiones:

Las opciones que ofrecen las aplicaciones actuales nos permiten desarrollar una dinámica de enseñanza-aprendizaje online del arte y el diseño que rompa las barreras de la distancia y genere una experiencia comparable a la presencial. 
La expectativa de éxito se basa en la implicación del docente, en su propia naturaleza colaborativa y/o cooperativa, y en el trabajo tanto dentro del horario lectivo, como fuera de él, que permita al alumnado participar aun a pesar de la diversidad de circunstancias de cada uno.

\subsection{Objetivo general}

Investigar las posibilidades de motivación de las clases virtuales presenciales de la enseñanza online del diseño, mediante el uso de estrategias de dinamización aplicadas a través de las posibilidades de las plataformas actuales.

A su vez, se pretende que estas estrategias liberen horas lectivas para el desarrollo de unas sesiones más prácticas, sin descuidar los contenidos teóricos de las asignaturas, poniendo en práctica opciones que se salgan de la exposición convencional de la clase docente habitual.

\subsection{Objetivos específicos}

- Diseñar propuestas prácticas aplicadas a las posibilidades de las herramientas de videoconferencia y el uso de las wikis para el desarrollo de técnicas de trabajo grupal colaborativo y cooperativo.

- Aumentar el tiempo dedicado a las prácticas de carácter técnico para una mejor capacitación laboral del alumno.

- Implicar la experiencia del estudiante en el proceso de aprendizaje.

- Capacitar a los alumnos en el uso de herramientas colaborativas en línea, desarrollando habilidades de trabajo en equipo a distancia. 
- Incentivar la implicación y el interés de superación de los alumnos mediante la puesta en común y los resultados compartidos.

\section{Marco teórico breve}

Antes de profundizar en las experiencias, que hemos rescatado de nuestro quehacer docente en la enseñanza del diseño, queremos presentar unos breves fundamentos teóricos, que nos ayudarán a articular el posterior desarrollo experimental.

Desde este punto de partida teórico vamos a hablar de tres aspectos importantes en el desarrollo de las estrategias de dinamización del aprendizaje. Por un lado, la importancia de la aplicación de la experiencia, elaprender haciendo. Este aprender haciendo tiene que desarrollarse en un ámbito específico, que será la enseñanza online, por lo que hablaremos brevemente del elearning. Este reto será posible gracias a la implicación del docente y a las estrategias de motivación e implicación, por lo que hablaremos de las características que recuperamos de la gamificación para nuestras experiencias docentes.

"Muchos estudios revelan que la mayor eficacia de los procesos de aprendizaje se da cuando hacemos y aplicamos, más que cuando simplemente escuchamos. Es decir, que todo método activo es preferible a uno pasivo (o menos activo), pues el aprendizaje se incrementa con la actividad" (Tourón y Marín, 2019, p. 16). Estamos ante la necesidad, lógica pero no siempre atendida, del aprendizaje significativo. Todo lo que enseñamos a nuestros alumnos debe formar parte del desarrollo de sus propias capacidades y debe posicionarlos ante el futuro mundo laboral con la adquisición de una serie de competencias, conceptuales, actitudinales y procedimentales, que le 
permitan desarrollar su trabajo de forma creativa y eficaz. "El diseño de estos materiales con tecnología interactiva rompe con los modelos de presentación lineal y permiten la simulación y recreación de la realidad consiguiendo con ello el aprendizaje por la experiencia" (Sánchez, 2015, p. 15).

Como decíamos, las experiencias que vamos a tratar son principalmente del ámbito del eLearning, ya que se enmarcan en una experiencia a distancia, sustentada por medios digitales y con la conexión a través de la web. La relación entre el docente y los estudiantes, y de los estudiantes entre ellos, será tanto síncrona como asíncrona.

Esta es una realidad a la que nos enfrentamos día a día y que nos ayuda al desarrollo de nuevas competencias docentes que, lejos de sustituir a las estrategias habituales, suponen un acercamiento de la enseñanza superior a una mayor diversidad de perfiles, sin restricciones geográficas o de movilidad en general. A su vez, las nuevas tecnologías nos permiten un doble aprendizaje de los contenidos y el uso de los medios.

El ámbito de desarrollo puede enmarcarse en lo que conocemos como eLearning:

E-LEARNING is the computer and network-enabled transfer of skills and knowledge. Application of e-learning includes computer-based learning, web-based learning, virtual education opportunities etc. Content is provided via the Internet, audio or video tape and CD-ROM etc. It can be self-paced or instructor-led and it also includes various media in the form of text, image, audio, video, animation etc. It is learner centric learning mechanism irrespective of time and distance. (Bhattacharya y Nath, 2016, p. 83) 
El profesor se convierte en eTeacher, que tendrá que desarrollar sus habilidades comunicativas a otro nivel, y la capacidad de mantener la atención e implicación de los estudiantes en el proceso de enseñanza-aprendizaje.

Ferreira et al. (2019) exponen que la práctica pedagógica de los docentes en elearning tiene una perspectiva multidimensional que se organiza en torno a tres dimensiones principales: conocimiento conceptual del profesor, estrategias pedagógicas y conocimiento tecnológico; con el conocimiento didáctico en el centro como conexión entre las tres. "El quid de este modelo es la interdependencia entre los conocimientos didáctico, pedagógico, tecnológico y la enseñanza aprendizaje en la modalidad de la enseñanza a distancia y e-learning" (Ferreira et al., 2019, p. 4).

Para lograr alcanzar los objetivos de implicación y motivación del alumnado se aplican ideas procedentes de la gamificación, transformando el aula en un espacio de trabajo colaborativo $y$, a su vez, en un aprendizaje a través de aspectos lúdicos. "Su objetivo es motivar a las personas a cambiar los comportamientos o desarrollar habilidades, o impulsar a la innovación” (Vélez, 2016, p. 30).

"Burke [...] considera a la gamificación como «el uso de mecánicas de juego y diseño de experiencias para comprometer digitalmente y motivar a las personas al cumplimiento de logros»" (Vélez, 2016, p. 30).Otros autores hablan de conceptos asociados a juegos sociales, que al fin y al cabo coinciden con algunos de nuestros objetivos en el aula virtual, ya que tratamos de incentivar la socialización entre los participantes de la sesión/actividad.

Romper con la clase magistral en diseño es imprescindible para conseguir una implicación en el proceso práctico y por ello las 
investigaciones y resultados de la gamificación nos aportan un conocimiento muy útil a aplicar en la enseñanza online del diseño."Corresponde a una metodología que se implementa para hacer de los contenidos tradicionales y necesarios en cada materia unos contenidos más interesantes y dinámicos" (Vélez, 2016, p. 31).

\begin{abstract}
"Lo que interesa no es enseñar, sino aprender, transferir el protagonismo de la actividad al estudiante, que es quien debe hacer suya la información y transformarla en conocimiento significativo y funcional para él. Ya no se trata de transmitir conocimientos, que por otra parte estarán desfasados en poco tiempo, sino de fomentar hábitos intelectuales". (Tourón y Marín, 2019, p. 17)
\end{abstract}

\title{
3.1. Descripción de las aplicaciones utilizadas
}

Dentro de este marco teórico breve, presentamos las aplicaciones que hacen posibles las dos experiencias que destacamos en este artículo.

Adobe Connect es un software desarrollado por Adobe Systems que permite el trabajo colaborativo a través de la videoconferencia. La aplicación ofrece salas virtuales para reuniones, creación e intercambio de información en diversos formatos a través del uso de la pizarra y los pods de compartir contenido.

Sus comienzos se remontan a 2003 con una aplicación precursora de la actual Adobe Connect, Presedia Publishing System, que en 2006 se fusiona con los productos de Macromedia dando lugar a la aplicación que actualmente se utiliza en UNIR para el desarrollo de las clases presenciales virtuales y el ámbito de una de las estrategias que vamos a describir más en profundidad. Comenzarán, en el mismo 2006, lanzando el Adobe Connect 6, pero el lanzamiento no será estable hasta septiembre de 2012 cuando lanzan la versión 9. 
Es un software independiente que no está asociado a otra plataforma educativa que lo acoja, esto permite el uso de las salas sin restricción horaria y pudiendo acceder desde diversos dispositivos ya que cuenta también con la versión app para dispositivos móviles. En la versión de escritorio requiere el uso de Adobe Flash Player y la instalación de un complemento (De Miguel y Yáñez, 2019).

La aplicación permite multitud de opciones de trabajo virtual, pero nos centraremos, más adelante, en aquellas que hemos aplicado en nuestras estrategias de dinamización de la enseñanza del diseño online.

La wikies el segundo recurso a presentar, es una palabra de origen hawaiano que significa "rápido".

Se inscribe dentro del conjunto de herramientas de lo que se ha denominado Internet 2.0, caracterizada por la transición de un usuario pasivo a otro que crea contenidos. En su conjunto estas herramientas se conocen como "software social". Desde el punto de vista educativo estas favorecen la colaboración, especialmente de forma remota (Adell, 2007).El aprendizaje cooperativo busca por un lado la implicación de los alumnos en pos de un objetivo común y por otro presenta una serie de estrategias didácticas que fomentan la motivación, mejorar el ambiente en el aula y favorecen el aprendizaje de habilidades sociales.

La wiki fue creada en 1994 por Ward Cunningham. Su objetivo era desarrollar toda la infraestructura y software que permitiera crear un sitio web con diversas páginas que fuera fácilmente editable usando un navegador web. Inicialmente no tenía fines docentes; su origen surge de la necesidad técnica de facilitar la comunicación entre programadores. 
Aunque original en ciertos aspectos, la wiki es en realidad heredera de una larga tradición informática de comunicación. De todas estas referencias previas destacan los editores textuales y de programación con control de cambios junto a las teorías y sistemas hipertextuales (Bush, 1945; Landow, 1995; Landow, 1997).

Pese a los muchos proveedores de editores de wikis que hay en la actualidad hay características que son comunes a todos ellos:

- Tiene dos estados: edición y visualización.

- La edición es sencilla y se realiza autónomamente desde cualquier ordenador con acceso a internet.

- Puede ser alterada por cualquier usuario o restringir el uso a unos usuarios concretos.

- Tiene una función de control de cambios que almacena todos los estados desde la creación

- Es un almacén de información que no queda "cerrado", se puede actualizar

- Incluyen un foro de discusión en cada página de la wiki y para la wiki en su conjunto.

\section{Método, desarrollo y resultados}

Antes de hablar de las estrategias individuales de cada uno queremos destacar brevemente otras estrategias que se están llevando al aula por miembros de DiSEA, como el uso de blogs para la presentación de las actividades, otras prácticas en directo en las sesiones, trabajos de dibujo con el uso de doble cámara, actividades en formato vídeo, etc. Algunas de ellas se basan en la interacción síncrona y otras en la asíncrona, pero todas ellas buscan la humanización de la enseñanza online a través de medios visuales y audiovisuales. 
La intervención del profesor en ambientes online [se centra] en el proceso de construcción del conocimiento en el ambiente virtual de aprendizaje. El enfoque [...] implica la participación en la comunidad de práctica, donde el aprendizaje no está considerado como un proceso de adquisición, sino de participación. [...] los profesores serán también orientadores con el objetivo de optimizar el pensamiento crítico, reflexivo y creativo de un estudiante más autónomo. (Ferreira et al., 2019, pp. 4-5)

En este apartado vamos a desarrollar dos estrategias diferenciadas:

(1) Prácticas de Brainstorming en el aula virtual con alumnos de diseño.

(2) El uso de wikis en estudios artísticos de enseñanza superior.

Posteriormente, en las conclusiones, hablaremos de los logros alcanzados con cada una de ellas.

\subsection{Brainstorming}

Una de las estrategias que vamos a presentar más en profundidad consiste en el desarrollo de sesiones de Brainstorming en las sesiones virtuales presenciales de las asignaturas de diseño. Habitualmente las sesiones se desarrollan con el profesor conectado con cámara y micro y los alumnos hablan por el chat o piden acceso para el uso del micro. En este caso se rompe la dinámica habitual de las sesiones y se establece una bidireccionalidad en la comunicación y el alumno se hace protagonista del proceso.

Se trata de orientar al alumnado hacia la responsabilidad de su propia formación mediante la acción y la participación con el objetivo de formar profesionales con la suficiente autonomía para 
el desarrollo de sus capacidades de innovación y creatividad. [...] la utilización de los juegos de simulación y la clase invertida guiada por el docente, pero donde las tareas son protagonistas frente al discurso magistral. (Sánchez, 2015, p. 14)

\subsubsection{Método}

Para llevar a cabo esta experiencia se hace uso de las opciones de la aplicación, introducida con anterioridad, de Adobe Connect. Esta nos permite distribuir a los alumnos en salas virtuales para que trabajen por grupos sin saber qué están haciendo el resto de compañeros. Tendrán que desarrollar el trabajo de forma grupal y posteriormente se expondrán las conclusiones al resto de la clase y se publicarán en el foro del campus virtual.

Para el desarrollo óptimo y productivo de la experiencia los estudiantes deberán conocer y poner en práctica las directrices del pensamiento divergente que exponemos a continuación.

\begin{tabular}{|l|l|}
\hline \multicolumn{2}{|l|}{ Directrices del pensamiento divergente } \\
\hline Aplazar Juicio & $\begin{array}{l}\text { No se trata de no tener juicio sino de no usarlo en } \\
\text { esta fase, la criba de buenas o malas ideas se hará } \\
\text { en la fase convergente. }\end{array}$ \\
\hline Combinar y Construir & $\begin{array}{l}\text { Unas ideas pueden ayudar a idear otras. Se trata } \\
\text { de construir, combinar, y mejorar ideas. }\end{array}$ \\
\hline Busque ideas alocadas & $\begin{array}{l}\text { Las ideas alocadas ayudan a generar otras ideas } \\
\text { más útiles. }\end{array}$ \\
\hline Buscar la Cantidad & $\begin{array}{l}\text { Cuantas más mejor, por el momento nos centramos } \\
\text { en la cantidad, no en la calidad. Centrarse en la } \\
\text { cantidad }\end{array}$ \\
\hline
\end{tabular}

Tabla 1. Directrices del pensamiento divergente. Fuente: CEF (s.f.) 
Así mismo, esta práctica es muy relevante para la comprensión del proceso de diseño, ya que la fase de ideación es una constante en todas las metodologías aplicadas al quehacer del diseñador.

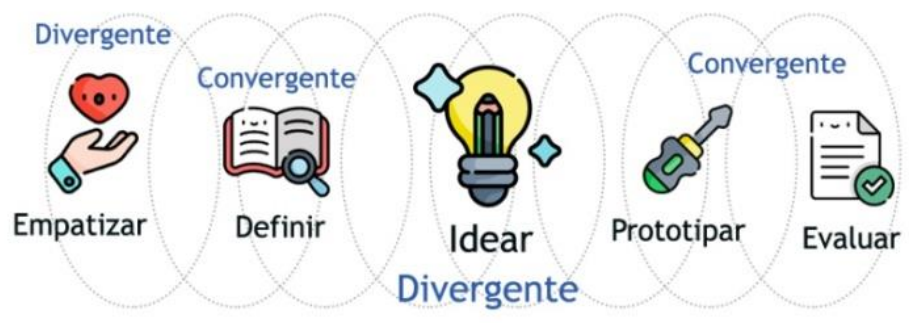

Figura 1. Proceso iterativo de diseño. DesignThinking. Fuente: Begoña Yáñez, 2019 (iconos de Freepik para flaticon.es).

\subsubsection{Desarrollo}

La actividad comienza con el planteamiento de la técnica de ideación que Alex Osborn desarrollaría en 1939, el Brainstorming. Se trata de una práctica que permita la comprensión de la técnica mediante la experiencia directa de la misma. Para comenzar se realiza una breve explicación de los objetivos del briefinga tener en cuenta, la descripción del mensaje gráfico que se requiere diseñar, apoyado en una investigación de los ejemplos y las formas más habituales hasta el momento. Una vez conocidos los datos necesarios se realiza el reparto aleatorio en grupos para el desarrollo de distintas versiones de una misma idea.

En cada sala se lleva a cabo una lluvia de ideas grupal y se recogen las mejores ideas para que, de vuelta a la sala principal, un portavoz que conecte el micro explique a la clase las conclusiones y 
muestre los ejemplos de bocetos que se hayan podido realizar en la sesión de ideación.

Fase 1

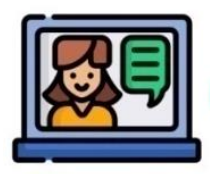

Explicación

$y$
Briefing
Fase 2

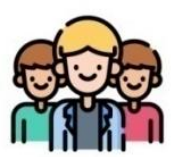

Reparto

aleatorio

en grupos
Fase 3

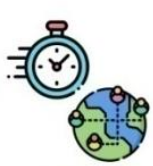

Tiempo

de
Fase 5

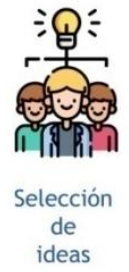

Exposición

del

portavoz

Figura 2. Esquema visual del proceso. Fuente: Begoña Yáñez, 2019 (iconos de Freepik para flaticon.es).

Las fases de ideación son de aproximadamente 15 minutos, en los que el docente va visitando las salas para asegurar que se ha comprendido la dinámica y todo el mundo está activo. Cerca del final del periodo se envía un mensaje a todas las salas, a través de las opciones de la plataforma, para recordarles el tiempo restante y advertirles que una vez cumplido se volverán a traer a la sala principal.

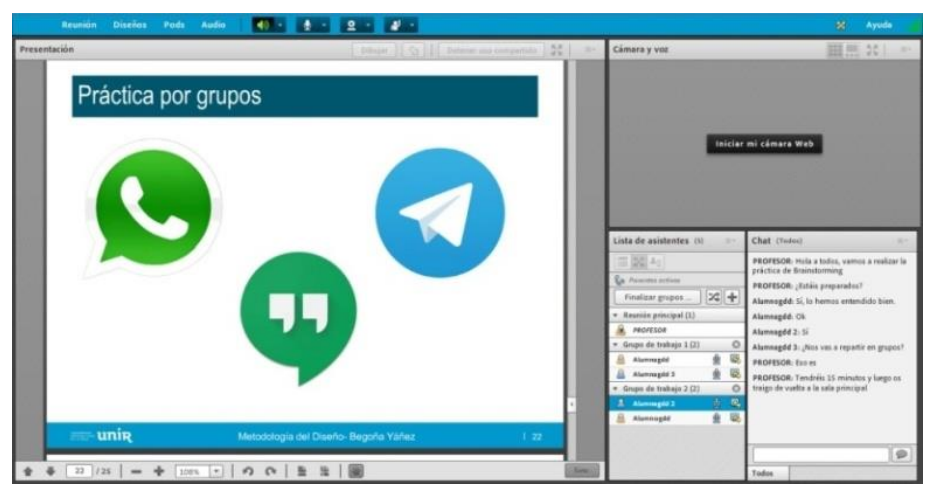

Figura 3. Ejemplo de división en salas en la aplicación de Adobe Connect.

Fuente: Begoña Yáñez, 2019. 


\subsubsection{Resultados}

A continuación, se presentan los resultados asociados a tres prácticas diferentes bajo la misma dinámica.

\section{Resultados práctica Mensajería Instantánea}

En la primera se plantea a los alumnos el reto de diseñar el isotipo de una nueva empresa de mensajería instantánea. La empresa ficticia quiere destacar en el mercado sin salirse de los convencionalismos habituales para este tipo de servicio. No tienen nombre todavía. Los grupos de trabajo tendrán que idear uno para el nuevo servicio de mensajería instantánea y plantear (al menos de forma teórica) color, forma y tipografía, y si es posible realizar algún boceto.

Se presentan como ejemplo las tres compañías más conocidas y utilizadas $y$ se establecen unas pautas comunes como convencionalismos a tener en cuenta:

- Los tres presentan formas circulares, dos de ellos completados por una flecha a modo de bocadillo, herencia del lenguaje del cómic.

- Los tres tienen elementos que representan la mensajería y/o la comunicación desde distintos puntos de vista: un teléfono, las comillas de las citas y un avión de papel.
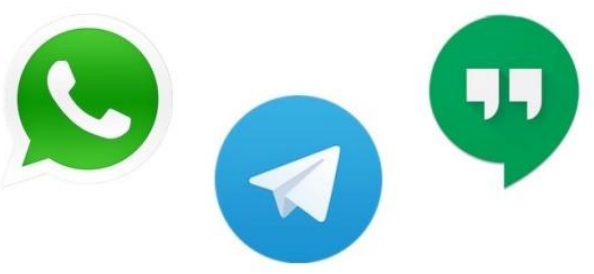
Figura 4. Ejemplos de WhatsApp, Hangouts y Telegram. Fuente:

http://news.playtochromecast.com/images/posts/20151019_4-extensionschrome.jpg

Como resultado destacado de esta práctica uno de los grupos presenta un ejemplo de isotopo de la empresa a la que han llamado $\mathrm{Hi}$, como símbolo de saludar, y conservan la forma de bocadillo, pero establecen la idea de una conversación, de ahí que el bocadillo tenga dos picos en lugar de uno. El uso de dos colores también quiere representar esta idea, y la fuente de palo seco para evitar romper con la sencillez simbólica de la idea.

En las figuras 5 y 6 podemos ver el ejemplo presentado por el grupo y la alternativa que se les propone, en base a la puesta en común en la sesióny el debate posterior del foro de compartir, sobre suavizar y contener las formas.
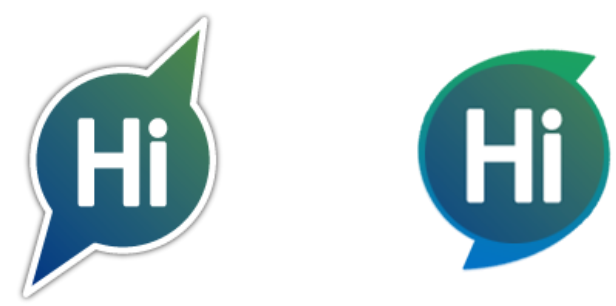

Figura 5. Ejemplo de resultado de la práctica de los isotipos de mensajería instantánea. Fuente: Rosa Ana Martínez Portero, 2018. Figura 6. Alternativa de Hi. Fuente: Begoña Yáñez, 2018.

\section{Resultados práctica Gluten Free}

En la segunda práctica se plantea a los alumnos repensar por grupos un cambio de imagen para los habituales logos que indican que un producto es apto para celíacos. Nuevamente tendrán que definir 
color, forma y tipografía (en caso se usarse) para replantear a esta idea. La variedad en este caso supone un punto de partida en el que no podemos establecer unos convencionalismos tan marcados como en la práctica anterior.

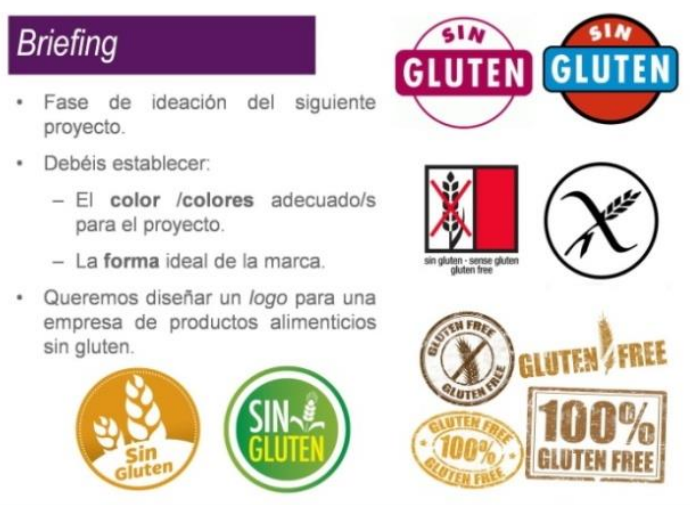

Figura 7. Presentación del briefing de la práctica Gluten Free. Fuente:

Begoña Yáñez, 2018.

Los resultados de esta práctica curiosamente desenlazan en el mismo punto para los dos grupos: la necesidad de hacer un logo que sea más amigable en lugar de uno con prohibición. Aun así, presentan sus nuevas ideas manteniendo la imagen a la que el usuario está más acostumbrado, pero con cambio de color, más centrado en los productos a destacar.

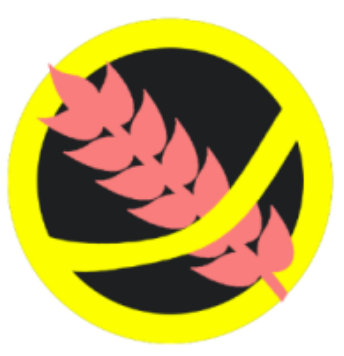


Figura 8. Ejemplo de boceto de uno de los equipos. Fuente: Manuel Iglesias Varela, 2018.

\section{Resultados práctica Red Social para Diseñadores}

Para esta práctica se les propone el diseño de un imagotipo (isotipo y logotipo que puedan usarse juntos o por separado) para una nueva red social para creativos/diseñadores gráficos. Una vez más deberán mantener los convencionalismos asociados a la forma de los imagotipos de este tipo de redes. Habrá que buscar un nombre, y elegir forma, color y tipografía adecuada. Como ejemplos, a modo de investigación de mercado, se presentan las redes sociales de creativos, de imágenes y de diseñadores actuales.

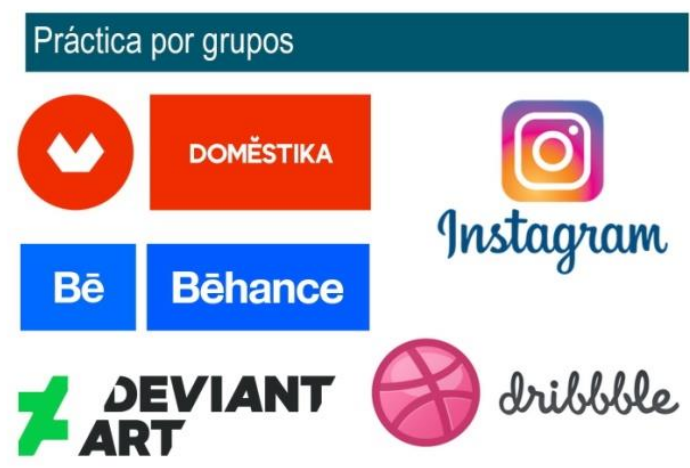

Figura 9. Presentación de ejemplos de redes existentes en la actualidad.

Fuente: Begoña Yáñez, 2018.

Los resultados de los grupos fueron muy variados. Un grupo se decantó por usar la palabra diseño en latín, consilio, con colores complementarios. Siguen construyendo y plantean una segunda 
versión de nombre, creashare, de crear y compartir, y acaban en una contracción en creshr.

\section{Oreshr}

\section{Tonsilio}

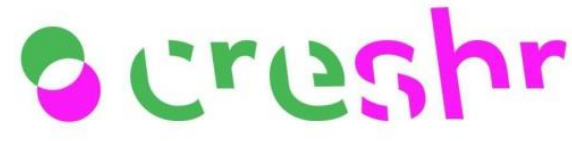

Figuras 10 y 11 . Ejemplos de diseños para la nueva red social Consilio y

Creshr. Fuente: Juan Manuel Ruiz Manso, 2019.

El otro grupo llega a la conclusión de llamarla PortLogo, combinando dos conceptos importantes en el diseñador: el portfolio y el logo, ambos representativos de su identidad profesional, y aprovechando la simbología del puerto marítimo y el del ordenador. Las letras P y L serán partes importantes de la identidad, como se puede ver en el ejemplo.

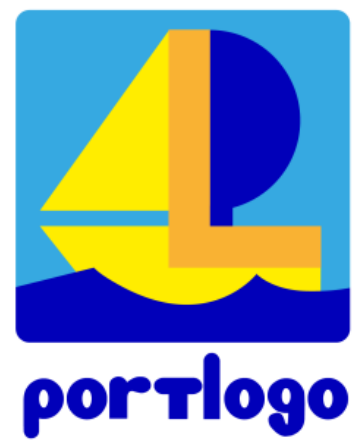

Figura 12. Ejemplo de diseño para la red social PortLogo. Fuente: Irantzu García Agirre, 2019.

Antes de pasar a las conclusiones de estas experiencias vamos a describir otra de las estrategias destacadas para este artículo. 


\subsection{Wikis}

La segunda estrategia se enmarca en un proyecto de innovación docente consistente en la elaboración de una wiki anual en la plataforma Wikispaces. El objetivo era implementar una página web donde aunar el esfuerzo colectivo de la totalidad de los estudiantes de fotografía. El resultado es un repositorio de fotógrafos relevantes en varias disciplinas (moda, reportaje, artística, entre otras) correspondientes a diversas épocas de la historia de la fotografía.

La intención del proyecto era reforzar la sensación de autoría de los alumnos. El documento tiene una audiencia, puede ser consultado por cualquier alumno de los grados de Diseño de Moda y Diseño Multimedia y Gráfico.

\subsubsection{Método}

El método pedagógico aplicado pretendía cambiar sustancialmente la forma en la que se imparten ciertos contenidos. En lugar de seguir la habitual exposición magistral de una serie de autores se pretende que sean los alumnos los que elaboren y suban esos contenidos. El enfoque de este ejercicio es ahora colaborativo y ayuda además a instruir a los alumnos en el uso de herramientas de este tipo de herramientas cada vez más comunes en entornos profesionales. Como beneficio adicional se pudo liberar tiempo de las horas lectivas que fueron aprovechadas para instrucción técnica.

Al finalizar este cuatrimestre se dio a los alumnos un cuestionario para que valoraran esta nueva experiencia en la que también se pretendía recabar información sobre su conocimiento 
previo de herramientas colaborativas, posibles mejoras en la mecánica del ejercicio y sus posibilidades de generalización.

\subsubsection{Desarrollo}

El desarrollo de este proyecto de innovación docente se realizó con alumnos de diseño gráfico y moda. Wikispaces es una herramienta que destaca por su funcionalidad. Su diseño estético es básico y las opciones de modificación de aspecto son limitadas.

La creación y gestión de la wiki creada en Wikispaces es responsabilidad del docente, quien selecciona los fotógrafos y crea sus apartados correspondientes.La redacción y preparación del trabajo sigue la metodología habitual de un informe prediseñado y no requiere que el alumno adquiera formación adicional.

En horario de clase se dedica alrededor de media hora para explicar cómo crear un usuario Wikispaces y el funcionamiento de la herramienta.Tras la presentación y explicación del ejercicio se procedió a asignar los fotógrafos y se dio un plazo de dos semanas para su ejecución.

La asignación de fotógrafos y grupos se realiza en clase mediante sorteo por extracción de papeletas. Este método se eligió por su sencillez y aleatoriedad. Se observó, con cierta sorpresa, emoción y "suspense" durante el proceso. Hubo interés por saber qué autor les había tocado a otros compañeros y una inmediata consulta en sus móviles para tomar un primer contacto con el fotógrafo asignado. Esto ayudó a tomar conciencia de lo positivo que resulta la introducción en clase de eventos lúdicos para dinamizar el proceso de enseñanza-aprendizaje y la conveniencia de desarrollar estrategias 
pedagógicas en las que el uso de dispositivos móviles esté más presente.

Terminada la actividad el profesor corrige y comenta brevemente en clase la calificación del trabajo de cada uno de los grupos. La revisión pública procura no incidir en los errores sino en lo más destacable de cada informe. El tiempo dedicado a este proceso sirve para que los alumnos tomen contacto con el resto de trabajos y adquiera referencias para su proyecto final. La nota obtenida no se hace efectiva hasta que los errores de los informes son subsanados.

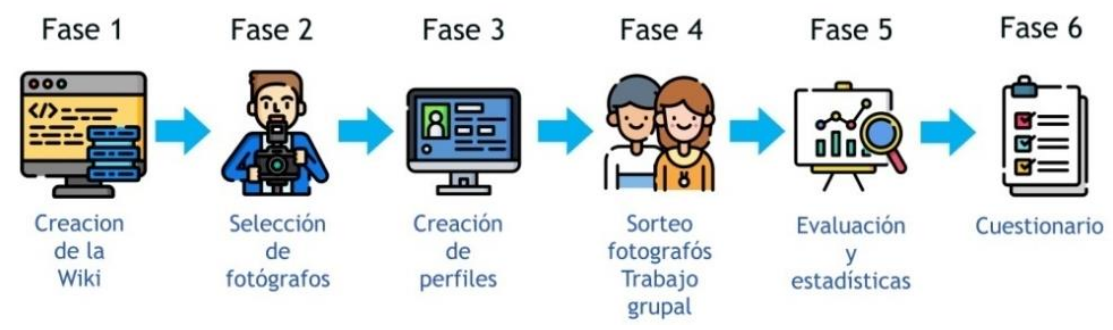

Figura 13. Esquema visual del proceso. Fuente: Begoña Yáñez, 2019 (iconos de Freepik para flaticon.es).

Como ya se ha mencionado el ejercicio se corregía online en la plataforma Wikispaces y se realizaba una valoración general del profesor de todos y cada uno de los informes. La nota se registraba en el aula virtual una vez los alumnos realizaban las correcciones, modificaciones y cambios señalados por el profesor. Este último paso es de gran importancia ya que es necesario que los alumnos tomen conciencia de que un trabajo debe quedar correctamente ejecutado. 


\section{Trabajo grupal}

Los grupos elaboran los informes en base a los fotógrafos seleccionados.La práctica totalidad de los informes fueron realizados en grupos de dos siguiendo esta estructura:

\begin{tabular}{|l|l|}
\hline \multicolumn{2}{|c|}{ Estructura de los informes } \\
\hline Texto & $\begin{array}{l}\text { Párrafo introductorio con los datos más relevantes, } \\
\text { párrafo donde se amplía la información sobre el } \\
\text { fotógrafo y por último un párrafo resumen donde se } \\
\text { valora globalmente el trabajo del autor. }\end{array}$ \\
\hline Imágenes & $\begin{array}{l}\text { Un total de seis imágenes con leyenda } \\
\text { identificativa. }\end{array}$ \\
\hline Enlaces comentados & $\begin{array}{l}\text { Cuatro referencias comentadas sobre el fotógrafo. } \\
\text { El documento al que remiten los enlaces podía ser } \\
\text { de todo tipo (páginas web, videos, documentación, } \\
\text { etc.). Se pedía a los alumnos que los enlaces fueran } \\
\text { variados en cuanto su tipología y contenido). }\end{array}$ \\
\hline
\end{tabular}

Tabla 2. Estructura de los informes de la Wiki. Fuente: Daniel Vega, 2019.

\subsubsection{Resultados}

Para presentar los resultados realizaremos un recorrido por las posibilidades de la herramienta apoyándonos en capturas de pantalla del trabajo realizado.

En la primera captura mostramos una visión de conjunto de la página Wikispaces y el informe correspondiente al fotógrafo Juan Gatti con la estructura antes mencionada (texto/imágenes/enlaces). La wiki se muestra en el modo de visualización con funcionalidades de usuario ORGANIZADOR. 


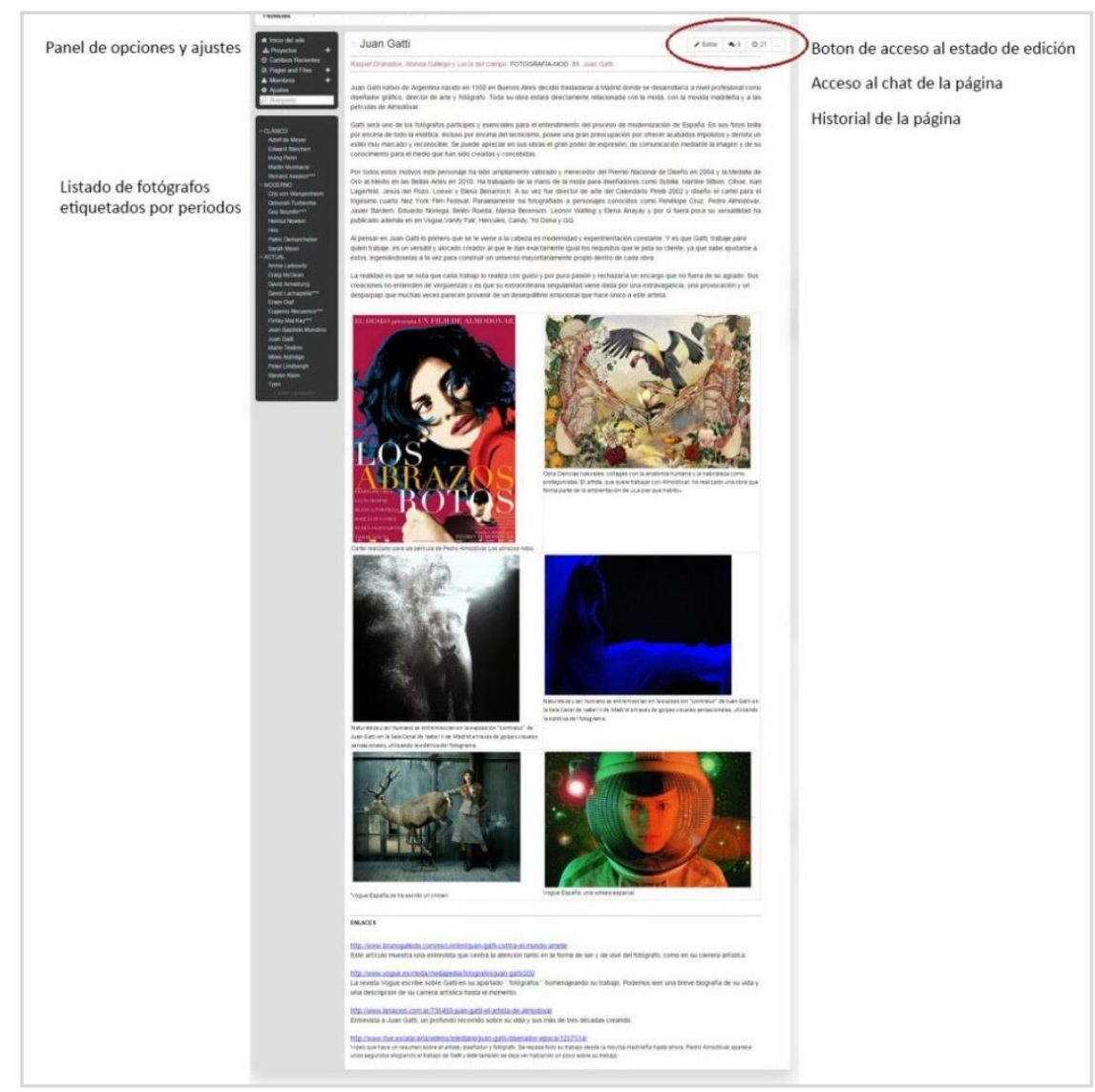

Figura 14. Ejemplo de página Wikispaces. Informe correspondiente al fotógrafo Juan Gatti. Fuente: Daniel Vega, 2015.

En la siguiente imagen mostramos el estado de edición de la página. Además de texto se pueden añadir notas marginales, tablas, enlaces a páginas web, enlaces a otras páginas de la wiki, documentos asociados a las wikis, vídeos y sonidos. Una sección de aplicaciones permite añadir entre otras muchas opciones calendarios, hojas de cálculos, sindicación de páginas (RSS), etc. 


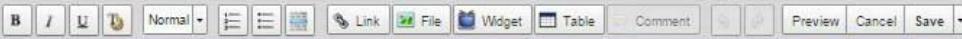

Raquel Granados, Ahinoa Gallego y Lucia del Campo. FOTOGRAFIA-MOD, 31. Juan Gatti

Juan Gatti nativo de Argentina nacido en 1950 en Buenos Aires decidió trasladarse a Madrid donde se desarrollaría a nivel profesional como diseñador gráfico, director de arte y fotógrafo. Toda su obra estará directamente relacionada con la moda, con la movida madrileña y a las películas de Almodóvar.

Figura 15. El estado de edición de la página. Fuente: Daniel Vega, 2015.

La aplicación cuenta con un espacio de comunicación, el chat, que sirve de intercambio de información y como evaluación de la actividad por parte del docente.

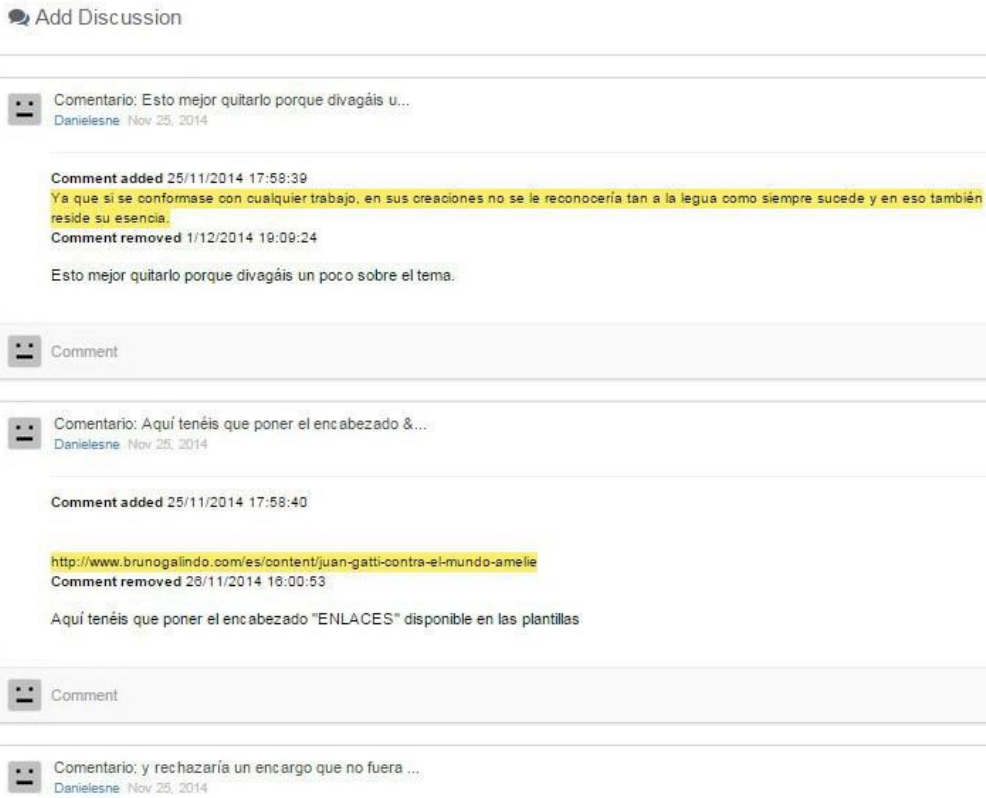

Figura 16. Chat de usuarios asociado a la página. Fuente: Daniel Vega, 2015.

A su vez, el docente puede consultar el historial para revisar la autoría de cada edición. 


\begin{tabular}{|c|c|c|c|c|c|c|}
\hline Juan Gatti & & & Editar & 29 & $\odot 21$ & \\
\hline Fecha & Compara & Autor & \multicolumn{4}{|c|}{ Comentario } \\
\hline Sep 6, $20151: 43 \mathrm{pm}$ & Seleccionar & a- Danielesne & & & & \\
\hline Sep 6, $20151: 43 \mathrm{pm}$ & Seleccionar & $\because$ Danielesne & & & & \\
\hline Sep 6, 2015 1,42 pm & Seleccionar & \#- Danielesne & & & & \\
\hline Sep 6, $20151: 39 \mathrm{pm}$ & Seleccionar & II Danielesne & & & & \\
\hline Dec 16, $20145: 42 \mathrm{pm}$ & Seleccionar & ID Danielesne & & & & \\
\hline $\operatorname{Dec} 7,20147.59 \mathrm{pm}$ & Seleccionat & a MOD31_DELCAMPO_LUCIA & & & & \\
\hline Dec 7, 20147:58 pm & Seleccionar & :- MOD31_DELCAMPO_LUCIA & & & & \\
\hline Dec 1, $20147: 09 \mathrm{pm}$ & Seleccionar & ت- MOD31_DELCAMPO_LUCIA & & & & \\
\hline Nov 26, $20144.00 \mathrm{pm}$ & Seleccionar & If Danielesne & & & & \\
\hline Nov $25,20145: 58 \mathrm{pm}$ & Seleccionar & \#- Danielesne & & & & \\
\hline Nov 19,2014 7:18 pm & Seleccionar & Z- raquelgranados & & & & \\
\hline * $122 \%$ & & & & $1-20$ & de 21 & \pm \\
\hline
\end{tabular}

Figura 17. Historial de la página desde su creación con la autoría de cada edición. Fuente: Daniel Vega, 2015.

Siguiendo con las opciones de revisión y evaluación de la participación, en la siguiente imagen podemos ver un ejemplo del control de cambios de una edición. En verde el texto y elementos añadidos, en rojo los eliminados.

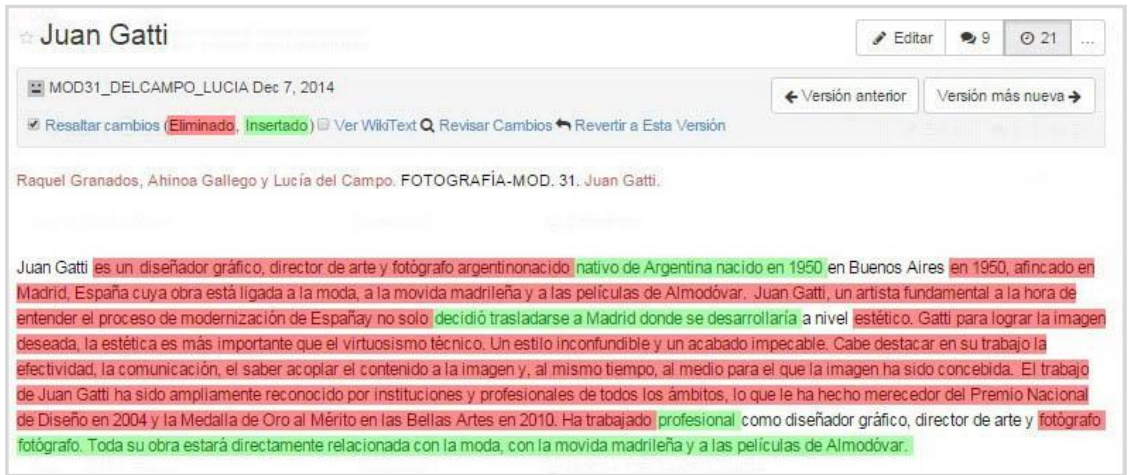

Figura 18. Ejemplo de control de cambios de una edición. Fuente: Daniel Vega, 2015. 
En las siguientes imágenes vemos las opciones de consulta de datos estadísticos de la actividad de los usuarios/alumnos. La sección de ajustes de Wikispaces (figura 19) nos permite tener acceso a un detallado informe estadístico de la actividad cronológica de la página.

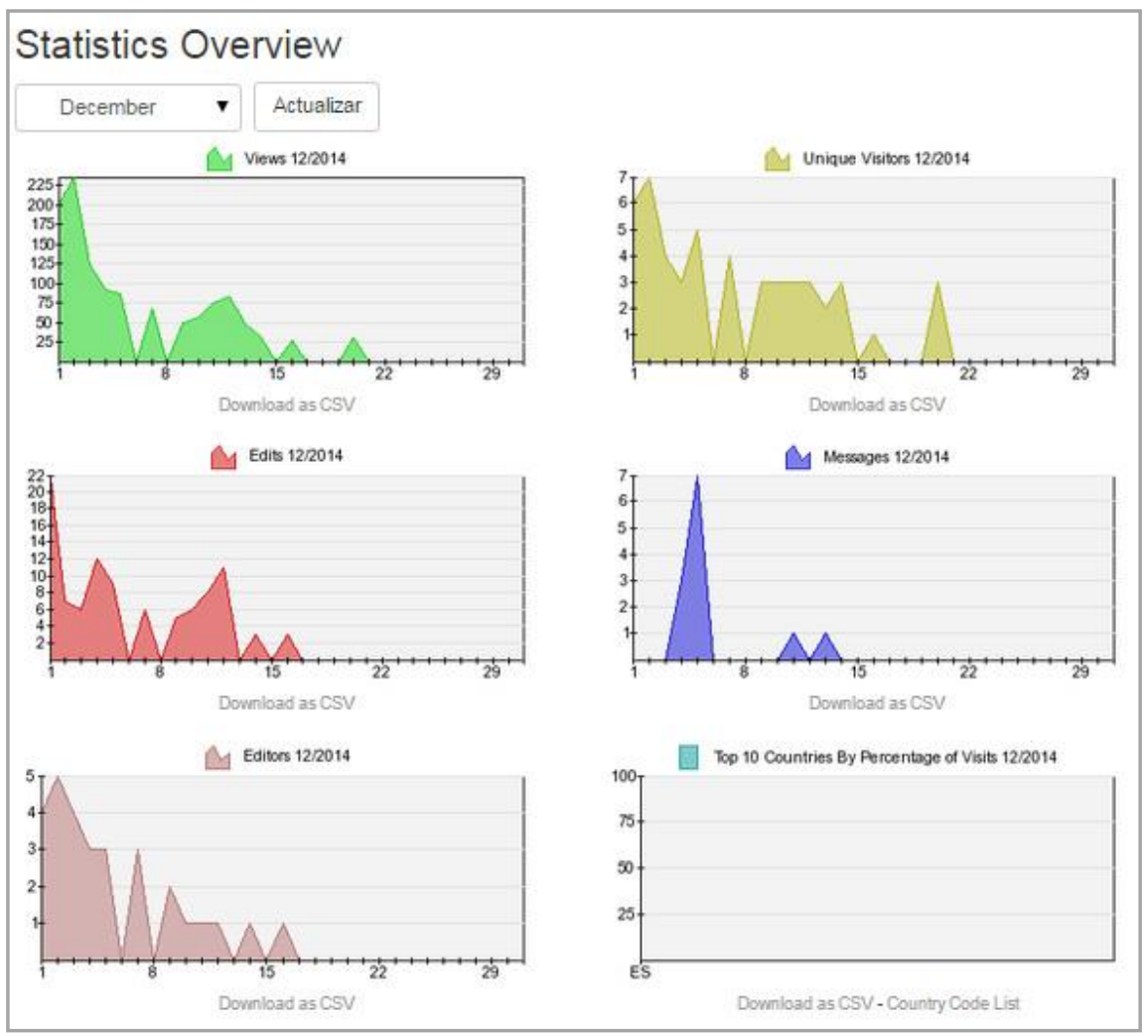

Figura 19. Sección de ajustes Wikispaces. Fuente: Daniel Vega, 2015.

Dentro de la sección de estadísticas podemos saber que fotógrafos han sido los más vistos, una información muy útil para replantear el listado de fotógrafos en futuros cursos. 


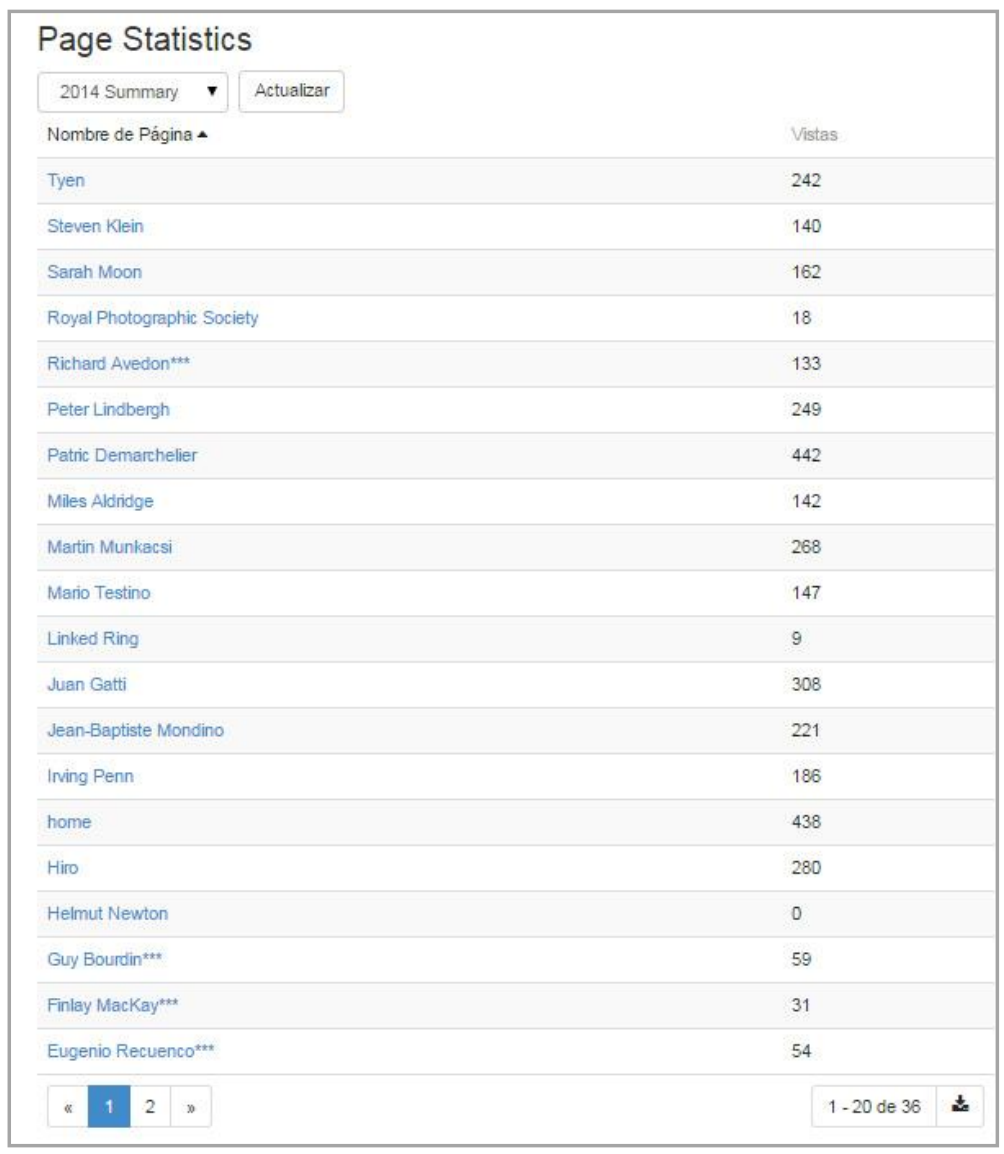

Figura 20. Sección de estadísticas. Fuente: Daniel Vega, 2015.

Por último, podemos recabar las estadísticas de cada uno de los usuarios. Wikispaces nos indica el número de ediciones de un usuario en concreto, la fecha y en qué páginas se hicieron. Es una herramienta muy útil para evaluar el grado de implicación del alumno y un argumento sólido para el profesor frente a la reclamación de un alumno por baja calificación. La estadística por usuario es extraordinariamente práctica para realizar una calificación asimétrica en trabajos grupales y además en caso de plagio es relativamente sencillo localizar al autor. 


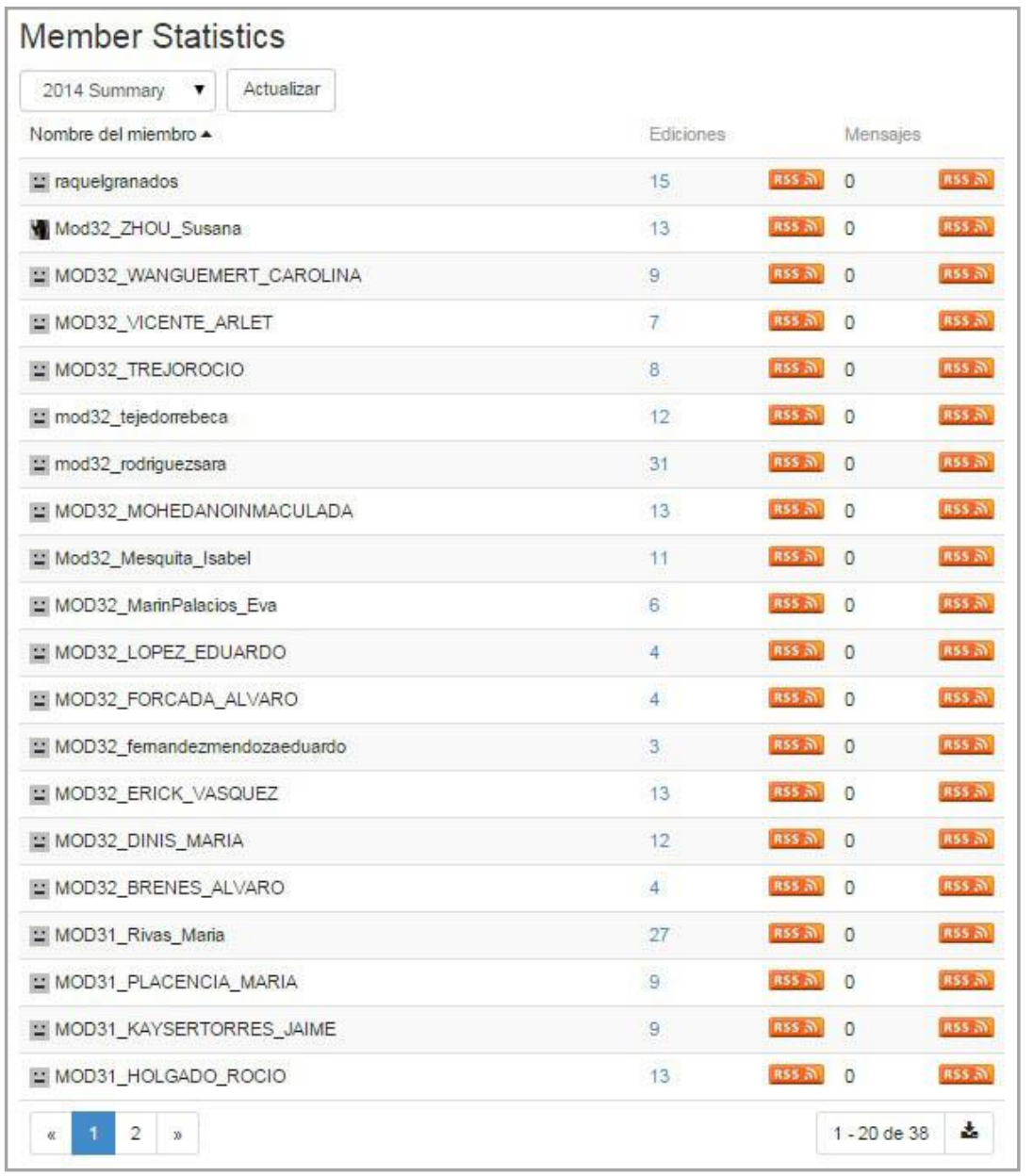

Figura 21. Estadísticas de los usuarios: Fuente: Daniel Vega, 2015.

\section{Cuestionario final}

Como indicábamos anteriormente, al finalizar cada uno de los tres cuatrimestres se entregó un cuestionario con 14 preguntas en el que 


\section{el alumno valoraba mediante una escala del 0 al 10 , en cada pregunta, siendo cero definido como "poco" y 10 como "mucho".}

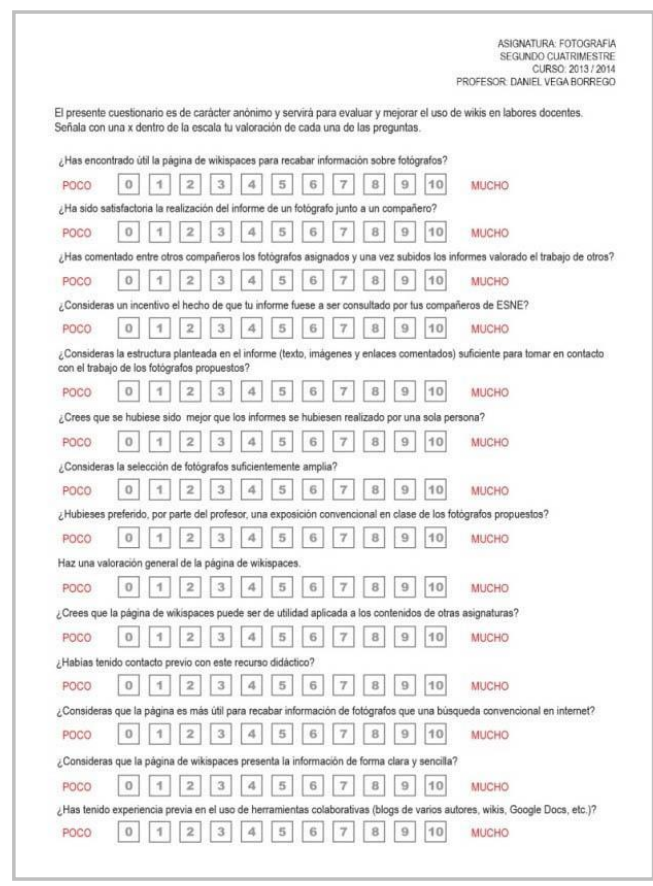

Figura 22. Cuestionario. Vista del alumno. Fuente: Daniel Vega, 2015.

\begin{tabular}{|l|r|}
\hline 1. ¿Has encontrado útil la página de wikispaces para recabar información sobre fotógrafos? & $\mathbf{6 , 6 9}$ \\
\hline 2. ¿Ha sido satisfactoria la realización del informe de un fotógrafo junto a un compañero? & $\mathbf{6 , 9 6}$ \\
\hline 3. ¿̇as comentado con otros compañeros los fotógrafos asignados y has valorado sus informes? & $\mathbf{4 , 8}$ \\
\hline 4. ¿Consideras un incentivo el hecho de que tu informe fuese a ser consultado por compañeros de ESNE? & $\mathbf{6 , 4 1}$ \\
\hline 5. ¿Consideras la estructura planteada suficiente para tomar contacto con el trabajo de los fotógrafos? & $\mathbf{7 , 5 5}$ \\
\hline 6. ¿Crees que hubiese sido mejor que los informes los hubiese hecho una sola persona? & $\mathbf{4 , 4 4}$ \\
\hline 7. ¿Consideras la selección de los fotógrafos suficientemente amplia? & $\mathbf{7 , 5 4}$ \\
\hline 8. ¿̇Hubieses preferido una exposición convencional del profesor en clase de los fotógrafos propuestos? & $\mathbf{4 , 7 7}$ \\
\hline 9. Haz una valoración general de la página de wikispaces. & $\mathbf{7 , 0 2}$ \\
\hline 10. ¿Crees que wikispaces puede ser de utilidad aplicada a los contenidos de otras asignaturas? & $\mathbf{6 , 6 6}$ \\
\hline 11. ¿Habías tenido contacto previo con este recurso didáctico? & $\mathbf{1 , 9 3}$ \\
\hline 12. ¿Consideras que la wiki es más útil para buscar información de fotógrafos frente a buscar en internet? & $\mathbf{7 , 1 5}$ \\
\hline 13. ¿Consideras que la página de wikispaces presenta la información de forma clara y sencilla? & $\mathbf{7 , 2 5}$ \\
\hline 14. ¿Has tenido experiencia previa con herramientas colaborativas (blogs varios autores, wikis, google docs, etc.? & $\mathbf{5 , 2 8}$ \\
\hline
\end{tabular}

Fuente 23. Muestra de las preguntas del cuestionario final. Fuente: Daniel Vega, 2015. 
ENCUESTA SOBRE LA PÁGINA WIKISPACES ELABORADA POR LOS ALUMNOS DEL GRADO DE MODA Y EL GRADO DISEÑO MULTIMEDIA Y GRÁFICO

TITULACIÓN: GRADO EN DISENNO DE MODA Y GRADO EN DISEÑO MULTIMEDIA Y GRÁFICO.

ASIGNATURAS: FOTOGRAFÍA: TRATAMIENTO DIGITAL DE LA IMAGEN (MODA) Y FOTOGRAFÍA (GRÁFICO Y MULTIMEDIA).

CURSOS: TERCERO (MODA) Y SEGUNDO (MULTIMEDIA Y GRÁFICO)

PROFESOR: DANIEL VEGA BORREGO

\begin{tabular}{|c|c|c|c|c|}
\hline & MUESTRA TOTA & MUESTRA TOTAL & MUESTRA TOTAL & TOTAL \\
\hline & MODA $13 \cdot 14$ & MULTIMEDIA 13-1. & MOOA $14-15$ & Alumnos \\
\hline NÚMERO DE ALUMNOS & 24 & 38 & 34 & 96 \\
\hline PREGUNTAS. & MEDIA & MEDIA & MEDIA & MEDIA \\
\hline 1. ¿Has encontrado útil la página de wikispaces para recabar información sobre fotógrafos? & 6,99 & 6,68 & 6,41 & 6,69 \\
\hline 2. ¿Ha sido satisfactoria la realizaciôn del informe de un fotógrafo junto a un compañero? & 6,95 & 7,05 & 6,88 & 6,96 \\
\hline 3. ¿Has comentado con otros compañeros los fotógrafos asignados y has valorado sus informes? & 5,24 & 5,05 & 4,11 & 4,8 \\
\hline 4. ¿Consideras un incentivo el hecho de que tu informe fuese a ser consultado por compañeros de ESNE? & 6,74 & 6,05 & 6,44 & 6,41 \\
\hline 5. ¿Consideras la estructura planteada suficiente para tomar contacto con el trabajo de los fotógrafos? & 7,41 & 7,47 & 7,79 & 7,55 \\
\hline 6. ¿Crees que hubiese sido mejor que los informes los hubiese hecho una sola persona? & 3,62 & 4,6 & 5,11 & 4,44 \\
\hline 7. ¿Consideras la selección de los fotógrafos suficientemente amplia? & 7,08 & 7,49 & 8,05 & 7,54 \\
\hline 8. ¿Hubieses preferido una exposición convencional del profesor en clase de los fotógrafos propuestos? & 5,58 & 4,68 & 4,05 & 4,77 \\
\hline 9. Haz una valoración general de la página de wikispaces. & 6,99 & 6,91 & 7,17 & 7,02 \\
\hline 10. ¿Crees que wikispaces puede ser de utilidad aplicada a los contenidos de otras asignaturas? & 7,24 & 6,41 & 6,35 & 6,66 \\
\hline 11. ¿Habias tenido contacto previo con este recurso didáctico? & 2,04 & 2,81 & 0,94 & 1,93 \\
\hline 12. ¿Consideras que la wiki es más útil para buscar información de fotógrafos frente a buscar en internet? & 7,53 & 6,73 & 7,2 & 7,15 \\
\hline 13. ¿Consideras que la página de wikispaces presenta la información de forma clara y sencilla? & 7,45 & 6,91 & 7,41 & 7,25 \\
\hline 14. ¿Has tenido experiencia previa con herramientas colaborativas (blogs varios autores, wikis, google docs, etc? & 5,2 & 5,6 & 5,05 & 5,28 \\
\hline
\end{tabular}

Figura 24. Relación de las medias de cada pregunta del cuestionario final. Fuente: Daniel Vega, 2015.

\section{Conclusiones}

Para establecer las conclusiones de nuestro recorrido estratégico por la dinamización de la enseñanza online, comenzaremos con algunas cuestiones particulares de cada experiencia y acabaremos con aspectos generales.

\subsection{Conclusiones Brainstoriming}

Las prácticas de lluvia de ideas online han resultado una actividad útil y dinámica a partes iguales. Los alumnos comienzan algo desorientados, pero pronto se animan a participar de la ideación y a tratar de tener material preparado para exponer frente al resto de la clase, ya que el otro grupo también va a presentar sus ideas. Estamos jugando de forma superficial con la gamificación en el aula, aunque la mayor recompensa es la felicitación por parte del docente y de sus 
compañeros, tanto en la sesión como en el foro de compartir los resultados.

La plataforma de Adobe Connect permite el trabajo en equipo entre personas de diversos lugares, sirviendo de lugar de trabajo colaborativo que dinamiza y salva las barreras de la no presencialidad, aportando una presencia virtual que cada vez se hace más real en el trato entre alumnos y con el docente. Una de las premisas que motivan estas acciones es la de humanizar la enseñanza online, y en el ámbito del diseño es más relevante si cabe ya que muchos de nuestros alumnos tendrán que desarrollar sus trabajos a través de equipos virtuales que se encuentren repartidos en distintas zonas geográficas.

La experiencia del brainstorming es una versión simplificada de la técnica de ideación, pero abre las puertas a romper el prejuicio que tienen algunos alumnos al trabajo en equipo en estos ámbitos. La experiencia del trabajo grupal les une, y potencia el interés de superación, siendo ellos los protagonistas de la clase.

Esta práctica combina la interacción síncrona, en la sesión, y la asíncrona, permitiendo al resto de alumnos seguir aportando ideas, enriqueciendo las existentes y aplicando un pensamiento divergente con posterioridad a la práctica en directo, mediante el uso de los foros del campus virtual.

Por estos motivos podemos concluir que se han logrado alcanzar satisfactoriamente los objetivos planteados al principio de la investigación asociados a la práctica del Brainstorming.

\subsection{Conclusiones a las Wikis}


La figura 23 muestra la media de los tres cuatrimestres en los que se realizó este proyecto. En azul se destacan aquellas preguntas más relacionadas con los objetivos presentados al principio, aunque del resto también se extrae información útil. Del análisis de datos cabe destacar que los alumnos ven como positivo y motivador que los informes sean accesibles. Optar por un acceso público del trabajo se tradujo en una mejora en el nivel de redacción con respecto a otros ejercicios donde solo mediaban el profesor y el alumno. Aunque de valoración casi neutra los alumnos no manifiestan preferir una exposición convencional por parte del profesor.

La valoración de Wikispaces como recurso es considerablemente alta. La mayoría prefiere este recurso como herramienta para informarse de los autores propuestos frente a internet. Pese a que los alumnos pueden ser considerados nativos digitales su conocimiento de Wikispaces es muy escaso. Los alumnos sí tienen un conocimiento mayor, aunque mediocre, de otras herramientas colaborativas. Los blogs y Google Docs son los más populares, aunque en muchos casos su conocimiento no significa que los usen con frecuencia.

En general el diseño del ejercicio has sido valorado positivamente. Los alumnos lo consideran útil, la estructura y contenidos de los informes suficientemente amplios y el número de fotógrafos analizados adecuado. También se valoró positivamente el carácter colaborativo del ejercicio, aunque hay también preferencia, por parte de ciertos alumnos, por un trabajo individual. El perfil creativo del alumnado puede explicar esta tendencia y la corrección asimétrica, que permite las Wiki, ayuda con esta renuencia. Respecto a la generalización del uso de Wikispaces en otras asignaturas los alumnos creen que sería positivo. Consideramos que la generalización puede ser conveniente en asignaturas teóricas, y menos relevante en aquellas prácticas. 
Hay ciertos aspectos en los que se esperaba un resultado más favorable. Uno de los objetivos era que los alumnos comentaran entre ellos los trabajos que les han asignado y la calificación de la pregunta sobre esa cuestión (4.8) es discreta. También se esperaba una calificación en la que los alumnos expresaran más claramente que preferían adquirir conocimientos del trabajo de fotógrafos mediante este ejercicio en lugar de una exposición magistral. Podemos deducir que los alumnos muestran a veces preferencia por enfoques tradicionales por su familiaridad y que la innovación docente puede encontrar resistencias no solo por parte del docente sino del propio alumno. En este sentido es importante explicar con detalle los objetivos, propósitos y beneficios del ejercicio para que los alumnos se involucren. Por otro lado, al haberse desarrollado este proyecto dentro del ámbito de las clases el uso del chat asociado a las páginas fue escaso.

\subsection{Conclusiones generales}

A modo de cierre general de las conclusiones aunamos los esfuerzos y resultados obtenidos en estas estrategias y en el desarrollo general de la práctica docente en la enseñanza del diseño y el arte.

Las experiencias realizadas, tanto las que aquí se muestran como otras desarrolladas por el grupo de investigación, nos llevan a una conclusión clara: el estudiante aprende de la experiencia y asimila mejor los contenidos teóricos si se respaldan con actividades que desarrollen su creatividad, su autonomía y la capacidad de aplicar al conocimiento a su día a día. Por ello retomamos las ideas iniciales que planteábamos a través de una cita de Tourón y Marín (2019, p. 18 ), en la que nos explican de forma precisa esta necesidad de formar 
personas capaces de desenvolverse en nuestra sociedad actual. Podemos establecer, con nuestros resultados y las reflexiones que nos transmiten nuestros alumnos, que conseguimos incentivar esa capacidad creativa, potenciando la inteligencia emocional, y un aprendizaje autodirigido con el apoyo o guía del docente. Este tipo de experiencias les conduce hacia el desarrollo de habilidades colaborativas, comunicativas y al desarrollo de la metacognición, significando un equilibrio adecuado entre las posibilidades tecnológicas del aprendizaje online y la importancia de la inteligencia inter e intrapersonal en la humanización de la enseñanza a distancia.

Agradecimientos:Este estudio es fruto del trabajo colaborativo entre ambosautoresen el entorno del grupo de investigación DiSEA (Diseño, Sociedad, Educación y Arte) de la Escuela Superior de Ingeniería y Tecnología de UNIR. La participación e implicación de cada uno de ellos se produce de forma tal que no existencoautoressino un trabajo común mérito de cada uno de ellos.

\section{Referencias:}

Adell, J. (2007). Wikis en educación. En Cabrero Almenara, J. y Barroso Osuna, J. (coords.). Posibilidades de la teleformación en el espacio europeo de educación superior (pp. 323-333). Granada: Editorial Magina.

Bhattacharya, S. y Nath, S. (2016). Intelligent e-Learning Systems: An Educational Paradigm Shift. International Journal of Interactive Multimedia and Artificial Intelligence, vol.4, n.2, 83-88. DOI: http://dx.doi.org/10.9781/ijimai.2016.4212 
Bush, V. (1945). As We May Think. Washington: Atlantic Monthly.

CEF. (s.f.). Divergent Thinking. Creative Education Foundation [sitio web]. Recuperado de http: / / www.creativeeducationfoundation.org/creativeproblem-solving/divergent-thinking/

De Miguel Álvarez, L., y Yáñez Martínez, M. B. (2019). Interacción persona a persona en la sociedad del s.XXI: la tecnología y el arte al servicio de la comunicación. Revista Internacional de Principios y Prácticas del Diseño 1 (1), 11-30. DOI: https://doi.org/10.18848/2641-4406/CGP/v01i01/11-30

Ferreira Nobre, A. M., Chenoll Mora, A., Melaré Vieira Barros, D., \& Setién Burgués, A. (2019). Tabla DK eLearning: optimización de la práctica docente en un ambiente online. Revista De Educación a Distancia, 1(59). DOI: https://doi.org/10.6018/red/59/03

Infante Moro, A., Santos Fernández, N, y Santiesteban García, P. (2007). La docencia on line en la universidad presencial. En Ayala Calvo, J. C. (coord.). Conocimiento, innovación y emprendedores: camino al futuro (pp. 237-244). Logroño: Universidad de La Rioja.

Landow, G.P. (1995). Hipertexto: la convergencia de la teoría crítica contemporánea y la tecnología. Barcelona: Paidós.

Landow, G.P. (Ed.) (1997). Teoría del Hipertexto. Barcelona: Paidós.

Sánchez i Peris, F. J. (2015). Gamificación. Education in the knowledge society (EKS), Vol. 16, №. 2, 13-15. DOI: http://dx.doi.org/10.14201/eks20151621315

Tourón, J. y Martín, D. (2019). Aprender y enseñar en la universidad hoy. Una guía práctica para profesores. Logroño: UNIR. 
Vélez Osorio, I. M. (2016). La gamificación en el aprendizaje de los estudiantes universitarios. Rastros Rostros, vol. 18, $n^{\circ} 33,27-$ 38. DOI: doi: http://dx.doi.org/10.16925/ra.v18i33.1683 